\title{
Bilgi Merkezi Web Sitesi Üzerindeki "Süreli Yayınlar” Butonunun Öyküsü
}

The story of the "Periodicals Button" on the Information Center web site*

\section{Gültekin Gürdal*}

\section{Özet}

Bu makale, yeni kurulan bir üniversitenin Bilgi Merkezi web sitesinde "Süreli Yayınlar" butonunun ne amaçla planlanarak kullanıma açıldığını ve teknik alt yapısının detaylarını anlatmakta ve güncel bir konu olan E- Dergilerin yönetimine, özelde ülkemiz, genelde uluslararası düzeyde yeni bir bakış açısı getirmektedir.

Anahtar sözcükler: E-Dergi Yönetimi, Süreli yayınlar, Sabancı Üniversitesi Bilgi Merkezi.

\begin{abstract}
This article explains the purpose the "Periodicals Button" on the web site of the Information Center at newly established university, Sabanci University was planned and launched for, and details of its infrastructure. This work also attempts to take a new perspective on the current topic of the administration of e-journals on a worldwide scale in general, and in our country, Turkey, in particular.
\end{abstract}

Keywords: E-Journal management, Serials, Sabancı University Information Center.

\section{Yeni Bir Üniversite}

Sabancı Topluluğu, Türkiye'nin en büyük ve etkin aile vakfı olan Hacı Ömer Sabancı Vakfı (VAKSA) önderliğinde, Sabancı Üniversitesinin kuruluş kararını 1994 yılında aldı. 
Ağustos 1995'te, 22 değişik ülkeden, çeşitli üniversite, bilim merkezi ve disiplinlere mensup 50'nin üzerinde bilim adamı, araştırmacı, öğrenci ve işadamı İstanbul'da düzenlenen arama konferansında biraraya geldi. Konferans salonunda, İstanbul'da kurulacak bir dünya üniversitesinin felsefesi oluşturuldu: "Birlikte yaratmak ve geliştirmek".

Sabancı Üniversitesi Eylül 1999‘da Tuzla’daki kampusuna taşındı ve Ekim ayında akademik yılına kapılarını açtı. Her alanda yetkin ve kendine güvenen, çok boyutlu ve bağımsız düşünce yeteneği ile donanmış, toplumsal sorumluluk bilincine sahip bireyler yetiştirmek görevine sahip üniversite; bilim ve teknolojik gelişmelere ve üretilen bilgilerin topluma yayılmasına katkıda bulunmayı da temel ilke olarak benimsemiştir.

Uzun ve ciddi planlamanın sonucunda üniversite EFQM (European Foundation for Quality Management) üyeliğine kabul edilmiştir.

\section{Bilginin Üniversite İçin Önemi}

Üniversitenin kuruluş çalışmaları 1997 yılında başlatılmıştır. Bu amaçla görevlendirilen beş yöneticiden birisi üniversitenin bilgi hizmetlerinden sorumlu olan direktörüdür. $\mathrm{Bu}$ durum üniversitenin bilgiye verdiği önemin en açık göstergesidir.

\section{Neden "Kütüphane" Yerine "Bilgi Merkezi”}

Üniversite yönetimi tarafından bilgi hizmetlerini yürüten birime "Bilgi Merkezi" adının verilmesinin kabul edilmesi, Türk üniversiteleri arasında bu alandaki ilk ve temel değişikliktir. Kısaca "mülkiyet yerine erişim" olarak adlandırılabilecek bu yeni mantığın nedenlerinden bazıları bilgi kaynağı fiyatlarındaki hızlı artış, yeni teknolojilerin sağladığı hızlı erişim olanakları, yayıncılığın değişen yüzünün bir parçası olan ve kullanıcı ile bilginin çok hızlı bir şekilde buluşturulmasını amaçlayan uyarı (Alerting) servisleri gibi ögelerdir. "Kütüphane" yerine "Bilgi Merkezi" olmakla, her bilgi parçasını toplamak ve saklamak yerine, mevcut olan tüm formatlardaki bilgiye erişim amaç edinilmiştir. Bu 
erişim önce bölgesel sonra ulusal daha sonra da uluslararası seviyede sağlanacaktır.

\section{Bilgi Merkezi}

Sabancı Üniversitesinin eğitim, öğretim ve araştırma programlarını destekleyen, öğretim elemanları, öğrenciler ve çalışanların her tür ve ortamdaki bilgi ve belge gereksinimlerini karşılayan, ulusal ve uluslararası ölçekte bilgi birikimi, kullanımı ve aktarımına destek olmayı amaçlayan Bilgi Merkezi, 9432 m2'lik kapalı alana sahiptir. Merkezin raf kapasitesi 300.000 cilttir. Toplam 600 kişilik oturma kapasitesine sahip olan Merkez, 56 elektronik donanımlı kişisel çalışma kareli, 13 çok fonksiyonlu grup çalışma odası ile birlikte toplam 480 internet bağlantı noktasına sahiptir.

Her tür ve formatta bilgi kaynağı içeren Merkezin koleksiyonu, Ağustos 2002 sonu itibarıyle 46,619 kitap, 10,539 görsel-işitsel kaynak, 6,956 basılı ve elektronik süreli yayın ve 48 veri tabanı olmak üzere toplam 64,162'e ulaşmıştır.

\section{Bilgi Merkezi Süreli Yayınlar Koleksiyonu}

Güncel bilginin bilinen ve kabul edilen önemi, genelde üniversitenin, özelde Bilgi Merkezi'nin "süreli yayınlar" koleksiyonuna ayrıcalıklı bir yer vermesine neden olmuştur. E-dergi yönetme projesi, sözü edilen ayrıcalık nedeniyle başlatılan bir çalışmanın sonucudur.

Süreli yayınlar koleksiyonu iki temel ögeden oluşmaktadır. Birincisi abone olunanlar ki bunlar iki grupta ele alınmaktadır: doğrudan abone olunanlar veya konsorsiyum aracılığıyla erişilenler. İkinci grup ise sağlayıcı (aggregators) firmaların veri tabanlarından sağlananlardır.

Hazırlanan projede, sağlama biçimi kullanıcıyı ilgilendirmediği için dikkate alınmamıştır. Sağlanan basılı veya elektronik bütün süreli yayınlar ile konsorsiyumlardan sağlananlar, klasik anlamda kataloglananlar OPAC üzerinden kullanıma açılmıştır. Bunların sayıları ve yıllara göre dağılımı aşağıdaki gibidir: (bu tabloyu yıl bazında birleştirdik, okuması daha kolay gibi) 


\begin{tabular}{|l|r|r|r|r|r|r|}
\hline & \multicolumn{2}{|c|}{1999} & \multicolumn{2}{c|}{$\mathbf{2 0 0 0}$} & \multicolumn{2}{c|}{2001} \\
\hline & Başlık & \multicolumn{1}{|c|}{ Yüzde } & \multicolumn{1}{c|}{ Başlık } & \multicolumn{1}{c|}{ Yüzde } & \multicolumn{1}{c|}{ Başlık } & \multicolumn{1}{c|}{ Yüzde } \\
\hline Biçim & & & & & & \\
\hline Basılı & 345 & 69 & 498 & 14 & 449 & 6,5 \\
\hline Basılı+Çevrim içi & 70 & 14 & 159 & 4,5 & 215 & 3,1 \\
\hline Tam metin & 13 & 2,6 & & & & \\
\hline Basılı+Tam metin & 61 & 12,2 & & & & \\
\hline $\begin{array}{l}\text { E-Dergi (Sadece } \\
\text { Web) }\end{array}$ & 11 & 2,6 & 14 & 0,4 & 2483 & 35,7 \\
\hline $\begin{array}{l}\text { Veri tabanları } \\
\text { (FT/FI) }\end{array}$ & & & 2883 & 81,1 & 3803 & 54,7 \\
\hline Toplam & $\mathbf{5 0 0}$ & $\mathbf{1 0 0}$ & $\mathbf{3 5 5 4}$ & $\mathbf{1 0 0}$ & $\mathbf{6 9 5 0}$ & $\mathbf{1 0 0}$ \\
\hline
\end{tabular}

\section{Projenin Öyküsü}

Yapılan beş yıllık planlama, elektronik süreli yayınların basılı ortama oranla daha hızlı gelişeceğini göstermiş; bu değişime uyum sağlayabilmek amacıyla "Süreli Yayın Yönetme Projesi” hazırlanmıştır. Bu proje ile; farklı yayınevleri ve sağlayıcılardan elde edilen süreli yayınlara ait, içerik mevcutlar (holding), format ve url adresi bilgilerinden oluşan bir ara yüz tasarlandı.

Ülkemizde ilk kez, dünyada ise 3-4 kurumla eş zamanlı olarak süreli yayınlar formatlarına ayrıldı (e-dergi, basılı, tam metin ve tam görüntü). Böylece erişilmek istenilen süreli yayına ait tüm bilgilerin tek ekranda birarada görülmesi amaçlandı.

\section{Projenin Adımları}

\section{Adım 1 : Nasıl Başlandı?}

Esas olarak sistem, her süreli yayın için bir html sayfası yaratma temeli üzerine kurulmuştu. Yani, 1999 yılında yaklaşık 500 süreli yayın için, 500 farklı html sayfası tek tek hazırlanmıştı. Bu sistemde, her dosya belli bir düzene göre isimlendiriliyor ve belli bir kalıp sayfası üzerine işlenip, harf sırası ile klasörlere yerleştiriliyordu. Kullanıcı ise, her harfin alt alta yazılıp, herbirinin işlendiği arayüzü kullanıyordu. Bu arayüzde her html sayfasında bulunan farklı yayınevi veya sağlayıcıların sayfasına link (bağlantı) bilgisi 
giriliyor; ayrıca kataloglanan yayınların OPAC'taki künyesine de bağlantı koyuluyordu. Bu işlemlerin tümü elle (manuel) yapılıyordu.

\section{Yıl Sonunda Karşılaşılan Problemler}

Sistemde yılın sonunda çeşitli sorunlar olduğu görüldü. Bunlar ana hatları ile:

1 Her bir süreli yayın sayfası ayrı ayrı yaratıldığından, yapılan küçük ya da büyük hataları bulmak ve düzeltmek zaman ve işgücü kaybına yol açmaktadır.

2 İstenen bir tasarım ya da içerik değişimi zor olmaktadır.

3 Yapı bir veri tabanında olmadığından fazla sayıda dosyayı yönetmek, insanüstü bir dikkat gerektiriyordu.

4 Sahip olunan süreli yayınlar arasında, verimli bir şekilde arama yapılamıyordu. Süreli yayınları gerektiğinde bulundukları yayımcılara göre listelemek mümkün olmuyordu.

5 Bütün bu olumsuzluklara süreli yayın koleksiyonundaki hızlı artış da eklendiğinde kurulan sistemin yapısının hantal ve yeniliklere kapalı yapısı ile ortaya çıkıyordu.

\section{Adım 2 : Ne Yapılabilirdi?}

Gittikçe genişleyen süreli yayın sayısı mevcut sistemin artık ömrünü tükettiğini göstermişti. Bu soruna çözüm olacak iki seçenek vardı; Var olan şirketlerle anlaşıp hali hazırda sattıkları veri tabanı yönetme ve sunma sistemlerini satın almak.

Ne yazık ki istenen bütün gereksinimleri karşılayacak bir sistem o zaman yoktu yada var olan sistemler Bilgi Merkezinin istekleri, çalışma tarzı, genel sistem ve felsefesi ile bağdaşmıyordu ve soruna tam çözüm getirmiyordu.

Çözüm, kendi gereksinimlerimize uygun sistemin yaratılması idi. Böyle bir çalışma 
sonucunda merkezin istekleri ve sorunları çerçevesinde özgün bir yapı geliştirmek daha kullanışı ve sağlam olacaktı. Üstelik böylece temel hedeflerimizden biri olan bir yayını aynı ara yüz ekranı ile farklı yayınevleri ve sağlayıcılara ulaştırmak da mümkün kılınacaktı.

\section{Ne yapıldı ve Nasıl Çalışıyor?}

Uzun sayılabilecek bir dönem sonunda, sistemin asıl iskeleti kullanıma açıldı. Proje çerçevesinde yapılanlar şu şekilde özetlenebilir:

1 Süreli yayınların toplu halde tutulacağı bir veri tabanı dosyası+sistemi yaratma

2 İstenen süreli yayınları baş harflerine göre listeleme

3 İstenilen süreli yayını gösterme

4 Süreli yayınlar arasında anahtar kelime ve başlık taraması yapabilme

5 Yayıncılara ve sağlayıcılara göre listeleme

\begin{tabular}{|l|l|l|l|l|l|l|l|l|}
\hline infonMafion CENTER & Home & Catalogue & Databases & E-Resources & Multi medya & Periodicals & Requests & Site Search \\
\hline
\end{tabular}

\begin{tabular}{|l|l|l|l|l|l|l|l|l|l|l|l|l|l|}
\hline A & B & C & D & E & F & G & H & I & J & K & L & M & \\
\hline N & O & P & Q & R & S & T & U & V & W & X & Y & Z & \# \\
\hline
\end{tabular}

Type the WORD(S) you want, then click Search

Search by: Keyword $\nabla$

Search for:

Şekil 1: Süreli Yayınlar Ana Sayfası 


\section{Teknik Alt Yapı}

\section{Genel Özellikler}

Yeni sistemin en önemli özelliği, süreli yayınları tek bir dosya içinde saklıyor olmasıdır. Yaklaşık 6500 süreli yayın, "csv" (comma seperated values file) dosyasında toplu bir halde saklanmaktadır. Burada kullanılan asıl kaynak excel dosyasıdır. Excel kullanmayı bilen herhangi birinin süreli yayınları güncellemesi çok kolay ve kısa bir işlem haline gelmiştir. Dosya her bir yayıncı için gereken sayıda sütün ve her bir süreli yayın için bir satırdan oluşmaktadır. Bu sayede, bir süreli yayının birden fazla yayıncı veya sağlayıcıda bulunup bulunmadığını kontrol etmekte kolaylaşmaktadır.

\begin{tabular}{|c|c|c|c|c|c|}
\hline & A & $\mathrm{B}$ & $\mathrm{C}$ & $\mathrm{D}$ & $E$ \\
\hline 1 & NAME 0 & iSSN 1 & PRiNT 2 & Print+EJ Yil 3 & Print + EJ Link 4 \\
\hline 2 & Applied Physics Letters & $0003-6951$ & & $1995--$ & http://ojps aip.org/aplo \\
\hline 3 & Journal Of Applied Physics & $0021-8979$ & & $1997 .$. & http://ojps aip.orgijapol \\
\hline 4 & Journal of Chemical Physics ${ }^{*}$ & $0021-9606$ & & $1997 .-$ & http://oips.aip.org/icpo/ \\
\hline 5 & $\begin{array}{l}\text { Journal Of Vacuum Science \& Technology A: } \\
\text { Vacuum, Surfaces And Films }\end{array}$ & $0734-2101$ & 2001-- - - - - - - & $1983-$ & http:/iojps aip orginstal \\
\hline 6 & $\begin{array}{l}\text { Journal Of Vacuum Science \& Technology B: } \\
\text { Microelctronics... }\end{array}$ & $1071-1023$ & 2001-- & 1983 -- & http://ojps aip orgijvstb/ \\
\hline 7 & Biochemistry & $0006-2960$ & & 1996-- & http://pubs acs orgjournalsi \\
\hline 8 & Chemistry of Materials & $0897-4756$ & & 1996-- & http://pubs.acs.org/journals. \\
\hline 9 & Environmental Science And Technology & $0013-936 x$ & & 1996-- & http:/ipubs acs orgjiournals! \\
\hline 10 & Journal of Physical Chemistry $A$ & $0022-3654$ & & 1996 -- & http:/ipubs acs.orgyjournalsi \\
\hline 12 & Journal Of The American Chemical Society & $0002-7863$ & & $1996--$ & http:/ipubs acs orginournals! \\
\hline 13 & Journal Of Chemical And Eng. Data & $0021-9568$ & & 1996 -- & http:/ipubs acs orgyjournals! \\
\hline 14 & Journal of Organic Chemistry & $0022-3263$ & & $1996--$ & http:/ipubs acs.orgijournals! \\
\hline 15 & Journal of Physical Chemistry $\mathrm{B}$ & & & 1996 -- & http:/ipubs acs orgyjournals! \\
\hline 16 & Langmuir & $0743-7463$ & & 1996 -- & http:/ipubs acs orgjournals! \\
\hline 17 & Macromolecules & $0024-9297$ & & $1996--$ & hittp:/ipubs acs orgijournalsi \\
\hline 18 & Physical Review A & $1050-2947$ & 1999-- & 1985 -- & http:/ipra.aps.orgi \\
\hline 19 & Physical Review $\mathrm{B}$ & $0163-1829$ & 1999-- & 1985 -- & http://prb.aps.org/ \\
\hline 20 & Physical Review C & $0556-2813$ & 1999-- & 1985 -- & http:/iprc.aps.orgi \\
\hline
\end{tabular}

Şekil 2: Excel Dosyasının Bir Bölümünden Görünüm

\section{Süreli Yayınlar Nasıl Listeleniyor?}

Listeleme işlemini için perl ile yazılmış bir program kullanılmaktadır. Bu programın yaptığı ası işlem, "periodicals_source.csv” adı verilen dosyada saklanan süreli yayınları, harflerine göre gruplayıp, istenen grubu alfabetik sırada, 100'erli bölümler halinde ve html formatında yazdırıp listelemektir. 
Number of Periodicals (b) : 313

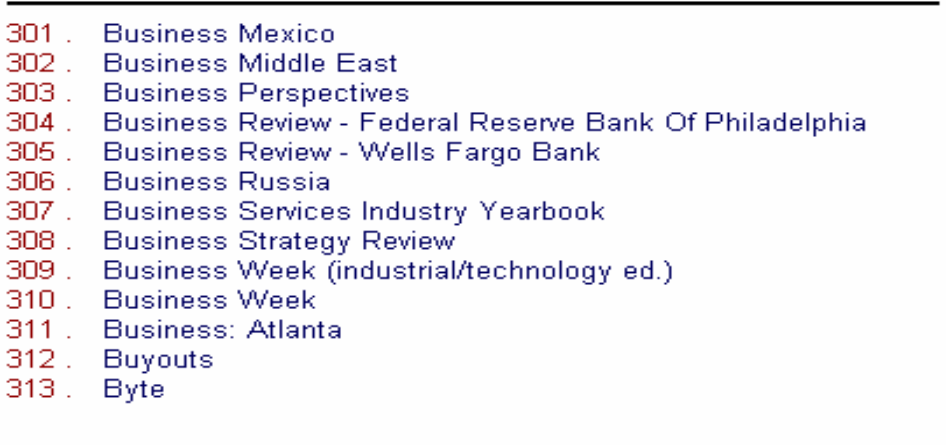

Go To Page: 1234

Şekil 3: Süreli Yayınların Listelenmesi

Oluşturulan listeler sadece süreli yayınların adlarından ve listede bulunan toplam süreli yayın sayısından oluşur. Her süreli yayının adına, o süreli yayına ait özel bir bağlantı gömülmüştür. Bu bağlantıya tıklanılması durumunda, o süreli yayın hakkında kapsamlı bilgiler içeren yeni bir sayfaya ulaşılır.

\section{Süreli Yayınlar Nasıl Görüntüleniyor?}

Görüntüleme işlemini yine perl programı gerçekleştirmektedir. Program hangi yayının görüntüleneceğine dair bilgiyi "periodicals_list.pl” programından alır. Asıl olarak yaptığı iş, kullanıcının istediği herhangi bir süreli yayının bilgilerini "periodicals_source.csv" dosyasından alarak html formatında kullanıcıya göstermektir. Bu bilgiler süreli yayının, varsa, ISSN numarası, içerik bilgisi, biçimi (format) ve bulunduğu yer (location) dir. Bir süreli yayın birden fazla yayıncı veya sağlayıcı firmanın veritabanında var olabileceği için o yayının birden fazla içerik (holding) ve yer bilgisine sahip olabileceğide dikkate alınmaktadır. Bu amaçla "periodicals_show.pl" programı her bilgiyi, ait olduğu kolondan alır, ve bu kolona karşılık gelen format bilgisini de ekleyerek ekrana yazdırır (Bkz. Şekil 4). 


\section{Journal of The ACM}

ISSN 0004-5411

\begin{tabular}{|l|l|l|}
\hline HOLDING & FORMAT & LOCATION \\
\hline $\mathbf{2 0 0 1}--$ & PRINT & SERIALS SHELF \\
\hline $\mathbf{1 9 5 4 - -}$ & EJOURNAL & ACM \\
\hline $\mathbf{0 1 . 1 1 . 1 9 9 5 - -}$ & FULL TEXT & ABI INFORM \\
\hline $\mathbf{0 1 . 0 1 . 1 9 9 1 - -}$ & FULL IMAGE & ABI INFORM \\
\hline $\mathbf{0 1 / 1 1 / 1 9 9 5 - -}$ & FULL TEXT & Social Science Plus [Proquest] \\
\hline $\mathbf{0 1 / 0 1 / 1 9 9 1 ~ - -}$ & FULL IMAGE & Social Science Plus [Proquest] \\
\hline $\mathbf{0 1 / 1 1 / 1 9 9 5 - -}$ & FULL TEXT & Applied Science \& Tech Plus [Proquest] \\
\hline $\mathbf{0 1 / 0 1 / 1 9 9 1 ~ - -}$ & FULL IMAGE & Applied Science \& Tech Plus [Proquest] \\
\hline
\end{tabular}

Şekil 4: Bir Süreli Yayınının Görüntülenebilen Detayları

\section{Avantajlar}

Eski sisteme kıyasla, yeni sistem birçok avantajı ve kolaylığı birarada sunmaktadır. Statik "html" kodları yerine dinamik "perl" ve her şekilde güncellenip şekillenebilecek "excel" dosyalarının bir bütünleşmesi olan sistemin getirdiği en büyük iki avantaj, zaman ve işgücü kazancıdır. Diğer bir üstünlüğü ise, "tarama (search)" özelliğinin istenilen her türlü kriteri kullanarak gerçekleştirilebilir olmasıdır. Şu an sadece -en çok tercih edilen"başlık (title)" ve "anahtar kelime (keyword)" üzerinden tarama yapılabilse de, gerektiğinde "yayıncı, sağlayıcı", "içerik” kriterleri de tarama özelliklerine eklenebilecek esnekliğe sahiptir. 


\section{Periodicals: Search Results}

Your Search: Iatin

1. Latin American Perspectives

2. Latin American Research Review

3. Latin Trade (English)

\section{Total Results:3}

Şekil 4: Tarama Sonuçları Listesi (bir de metin içindeki anlatılan kısma (Bkz. Şekil 5) şeklinde eklenirse daha iyi olur)

Web sayfalarının farklı dillerde hazırlanması gerektiğinde, sistemin dinamikliği sayesinde sayfaların tek tek her dil için oluşturulması yerine, perl kodlarında bir iki küçük değişiklik ile kullanıcıya sunulabilmektedir.

\section{Projenin Geleceği İçin Planlar}

Yapısı itibari ile dinamik olan sistem, yeni istekler ve tercihler çerçevesinde gelişmeye ve büyümeye devam edecektir. Üzerinde çalışılan ve yakın gelecekte kullanıma açılması planlanan bazı projeler şunlardır:

1 Güncelleme işlemlerinin tamamının web üzerinden yapılmasını sağlayacak bir ek yazılım hazırlanmaktadır. Bu ek yazııımla sistemi tanımayan yetkili personelin çok kolay bir şekilde veri tabanını güncelleme, yeni yayınlar ekleme ve çıkarma gibi fonksiyonları yapabilmesine olanak sağlanmış olacaktır.

2 Sistemin daha fazla arama kriterleri üzerine kurulu bir yapıya dönüştürülmesi.

3 Belli bir süre için kullanımı kııtllanmış (ambargolu) yayınlara, kullanııının hangi süreler, format ve yayıncı/sağlayıcılarda ulaşamayacağını gösteren bilgi notu eklenmesi.

4 Şuan tek tek veri tabanı dosyasına kaydedilmekte olan süreli yayın 
bilgilerinin otomatik kaydının sağlanması.

5 Süreli yayın bilgilerini doğrudan yayıncı veya sağlayıcı firmaların kendi sunucularından alınmasını sağlayacak sistemin hazırlanması. 